\title{
Design, Fabrication and Testing of Carbon Fiber Reinforced Epoxy Drive Shaft for All Terrain Vehicle using Filament Winding
}

\author{
Suhas Yeshwant Nayak, Nishank Minil Amin, Srinivas Shenoy Heckadka, Vishal Shenoy P, Ch. Sravan Prakash and \\ Ruthvik Mabbu
}

Department of Mechanical and Manufacturing Engineering, Manipal Institute of Technology, Manipal Academy of Higher Education, Manipal, Karnataka, India - 576104

\begin{abstract}
Filament winding is a composite material fabrication technique that is used to manufacture concentric hollow components. In this study Carbon/Epoxy composite drive shafts were fabricated using filament winding process with a fiber orientation of $\left[85_{2} / \pm 45_{2} / 25_{2}\right]_{\mathrm{s}}$. Carbon in the form of multifilament fibers of Tairyfil TC-33 having 3000 filaments/strand was used as reinforcement with low viscosity epoxy resin as the matrix material. The driveshaft is designed to be used in SAE Baja All Terrain Vehicle (ATV) that makes use of a fully floating axle in its rear wheel drive system. The torsional strength of the shaft was tested and compared to that of an OEM steel shaft that was previously used in the ATV. Results show that the composite shaft had $8.5 \%$ higher torsional strength in comparison to the OEM steel shaft and was also lighter by $60 \%$. Scanning electron microscopy (SEM) micrographs were studied to investigate the probable failure mechanism. Delamination, matrix agglomeration, fiber pull-out and matrix cracking were the prominent failure mechanisms identified.
\end{abstract}

\section{Introduction}

Drive shafts serve the purpose of connecting the differential to the wheel hubs in automotive vehicles [1]. SAE Baja vehicle has a competition regulated standard $10 \mathrm{HP}$ engine [2] and makes use of a centrifugal continuously variable transmission (CVT) coupled to a custom designed two stage reduction single speed gearbox in a spool configuration to drive its rear wheels. A conventional OEM drive shaft has three major components - inboard CV joint, shaft element, outboard $\mathrm{CV}$ joint [1]. In order to minimise transmission losses and unsprung mass of the car which ultimately improves ATV performance it is essential to lower the weight of every component possible due to the limited power available. The shaft element of the OEM drive shaft being used weighs about $2.5 \mathrm{~kg}$, providing ample room for weight reduction by the use of composite materials which have a lower density in comparison to steel. Carbon fiber is a reinforcing material that is widely used with a suitable resin due to its high strength and modulus [3]. Carbon fiber - epoxy resin combination provides the best strength to weight ratio in comparison to glass fiberepoxy or aramid - epoxy systems $[4,5]$. Since the shaft is to be used as a fully floating axle it has to take up only torsional loading caused by acceleration and braking of the vehicle. Hence ideal stacking sequences for a shaft undergoing torsional loading along with negligible axial and bending loads is $\left[90_{2} / \pm 45_{2} / 0_{2}\right]_{\mathrm{S}}[6,7,8]$. Calculations for all material parameters are based on the type of fiber and epoxy. In addition to this the design parameters of the shaft like length, diameter and thickness are also considered $[5,9]$.

This study aims to evaluate and compare the torsional strength of steel drive shaft to that of a carbon/epoxy composite shaft. The composite shaft is fabricated by filament winding process with a winding pattern of $\left[85_{2} / \pm 45_{2} / 25_{2}\right]_{\mathrm{s}}$. against an ideal winding pattern of $\left[90_{2} / \pm 45_{2} / 0_{2}\right]_{\mathrm{S}}$ due to machine constraints. The composite shafts were cured in a hot air oven. SEM micrographs are used to study the potential failure mechanisms, to verify if the composite shaft can be a potential replacement of the OEM steel shaft.

\section{Materials and Methods}

\subsection{Materials}

Tairyfil TC33 carbon fibers were chosen as the reinforcement. Fibers were procured from Hindoostan Composites, Mumbai. It has 3000 filaments in each strand with a yield Tex of $800 \mathrm{~g} / 1000 \mathrm{~m}$. The tensile strength of the fiber is $3450 \mathrm{MPa}$, tensile modulus is 230 $\mathrm{GPa}$, density is $1.8 \mathrm{~g} / \mathrm{cm}^{3}$, elongation of $1.5 \%$ and each filament has a diameter of $7 \mu \mathrm{m}$ [10]. A low viscosity resin is preferred while performing filament winding [11] and hence the L12- K6 epoxy-hardener system was chosen and procured from Atul Ltd. India. The neat polymer has a tensile strength of 55-70 $\mathrm{MPa}$, tensile 
modulus of 2.5-4.0 GPa and tensile elongation of 1.5-3.0\% [12].

\subsection{Calculations}

All nine material parameters $E_{11}, E_{22}, E_{33}, G_{12}, G_{13}, G_{23}, v_{12}$, $v_{13}$ and $v_{23}$ use the following nomenclature: the first subscript represents the loading direction and the second subscript represents the direction in which the particular property is measured as seen in Figure 1.

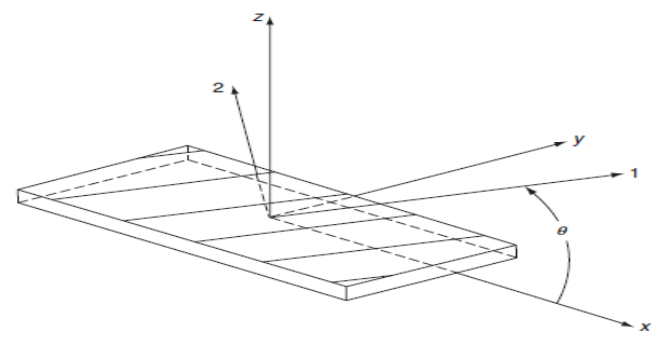

Figure 1: Definition of principle axes (1 and 2) and loading $\operatorname{axes}(\mathrm{x}$ and $\mathrm{y}$ ) for a lamina [9]

The following parameters were taken as inputs and base reference values:

Length of shaft $-300 \mathrm{~mm}$

Maximum external diameter $-28 \pm 0.1 \mathrm{~mm}$

Thickness of shaft $-4 \pm 0.05 \mathrm{~mm}$

Laminate thickness $(t) \sim 0.33 \mathrm{~mm}$

Maximum torque applied by gearbox to shaft $-650 \mathrm{Nm}$

Failure of torque of OEM steel shaft $-1630 \mathrm{Nm}$

Factor of safety for design torque -2.5

Volume fraction of fiber $-25 \%$

Poisson's Ratio of reinforcement - 0.2 [13]

Poisson's Ratio of matrix - 0.35 [13]

$$
E_{11}=E_{f} V_{f}+E_{m} V_{m}
$$

$\mathrm{E}_{11}$ : Young's modulus of the composite in the direction of fiber

$E_{f}$ : Young's modulus of the fiber

$V_{f:}$ volume fraction of the fiber

$E_{m}$ : Young's modulus of the matrix

$V_{m}$ : volume fraction of the matrix

$$
E_{22}=E_{f} E_{m} /\left(E_{f} V_{m}+E_{m} V_{f}\right)
$$

$E_{22}$ : Young's modulus of the composite perpendicular to the fiber

$$
v_{12}=v_{f}^{*} V_{f}+v_{m} * V_{m}
$$

$v_{12}$ : the ratio of strain in direction 2 to the applied strain in direction 1

$v_{f:}$ Poisson's ration of the fiber

$v_{m}$ : Poisson's ratio of the matrix

$$
\begin{gathered}
v_{21}=\left(E_{22} / E_{11}\right) * v_{12} \\
G=E / 2(1+v) \\
G_{12}=G_{f}^{*} G_{m} /\left(G_{f}^{*} V_{m}+G_{m} * V_{f}\right)
\end{gathered}
$$

$G=$ rigidity modulus

For special orthotropic lamina $(\theta=0$ or 90$)$ the equation can be written as:

$$
\left[\begin{array}{c}
\sigma_{x x} \\
\sigma_{y y} \\
\tau_{x y}
\end{array}\right]=\left[\begin{array}{ccc}
Q_{11} & Q_{12} & 0 \\
Q_{21}\left(=Q_{12}\right) & Q_{22} & 0 \\
0 & 0 & Q_{66}
\end{array}\right]\left[\begin{array}{c}
\xi_{x x} \\
\xi_{y y} \\
\gamma_{x y}
\end{array}\right]
$$

Stiffness matrix

' $\sigma$ ' represents the stress in a specific direction

' $\xi$ ' represents the strain in the specific direction

$$
\begin{gathered}
E_{11} /\left(1-v_{12} * v_{21}\right)=Q_{11} \\
v_{12} * E_{22} /\left(1-v_{12} * v_{21}\right)=Q_{12}=Q_{21} \\
E_{22} /\left(1-v_{12} * v_{21}\right)=Q_{22} \\
G_{12}=Q_{66}(8)
\end{gathered}
$$

For general orthotropic lamina $(\theta \neq 0$ or 90$)$ the values of

$$
Q_{11}, Q_{22}, Q_{12}, Q_{22} \text { change to } q_{11}, Q_{22}, Q_{12}, Q_{21} \text {. }
$$

$q_{11}=Q_{11} \cos ^{4} \theta+2\left(Q_{12+} 2 Q_{66} \sin ^{2} \theta \cos ^{2} \theta+Q_{22} \sin ^{4} \theta\right.$

$q_{22}=Q_{22} \cos 4 \theta+2(Q 12+2 Q 66) \sin 2 \theta \cos 2 \theta+Q_{11} \sin 4 \theta(12)$

$q_{12}=Q_{12}\left(\sin ^{4} \theta+\cos ^{4} \theta\right)+\left(Q_{11}+Q_{22}-4^{*} Q_{66}\right) \sin ^{2} \theta \cos ^{2} \theta(13)$

$\left[\begin{array}{l}N x \\ N y \\ N x y \\ M x \\ M y \\ M x y\end{array}\right]=\left[\begin{array}{llllll}A_{11} & A_{12} & A_{31} & B_{11} & B_{12} & B_{13} \\ A_{21} & A_{22} & A_{23} & B_{21} & B_{22} & B_{23} \\ A_{31} & A_{32} & A_{33} & B_{31} & B_{32} & B_{33} \\ B_{11} & B_{12} & B_{13} & D_{11} & D_{12} & D_{13} \\ B_{21} & B_{22} & B_{23} & D_{21} & D_{22} & D_{23} \\ B_{31} & B_{32} & B_{33} & D_{31} & D_{32} & D_{33}\end{array}\right]\left[\begin{array}{c}\xi_{\mathrm{x}} \\ \xi_{\mathrm{y}} \\ \gamma_{\mathrm{xy}} \\ \mathrm{K}_{\mathrm{x}} \\ \mathrm{K}_{\mathrm{y}} \\ \mathrm{K}_{\mathrm{xy}}\end{array}\right]$

$N_{x x}=$ normal force resultant in the $\mathrm{x}$ direction (per unit width)

$N_{y y}=$ normal force resultant in the y direction (per unit width)

$N_{x y}=$ shear force resultant (per unit width)

$M_{x x}=$ bending moment resultant in the yz plane (per unit width)

$M_{y y}=$ bending moment resultant in the xz plane (per unit width

$M_{x y}=$ twisting moment (torsion) resultant (per unit width)

$K_{x}, k_{y}=$ bending curvatures of the laminate

$K_{x y}=$ twisting curvature of the laminate as shown in Figure 2.
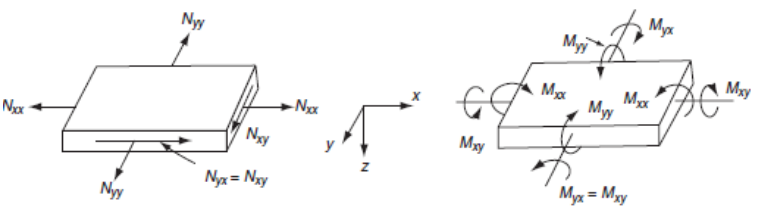

Figure 2: In-plane, bending, twisting loads applied on a laminate [9]

$[A]=$ extensional stiffness matrix for the laminate $[B]$ $=$ coupling stiffness matrix for the laminate

$[D]=$ bending stiffness matrix for the laminate

$$
A_{m n}=\sum_{j=1}^{N}(Q m n)_{j}\left(h_{j}-h_{j-1}\right)
$$

$h_{j}$ : distance of the top end of the $j^{\text {th }}$ laminate from the centre plane

$h_{j-1}$ : distance of the bottom end of the $j^{\text {th }}$ laminate from the centre plane as seen in Figure 3.

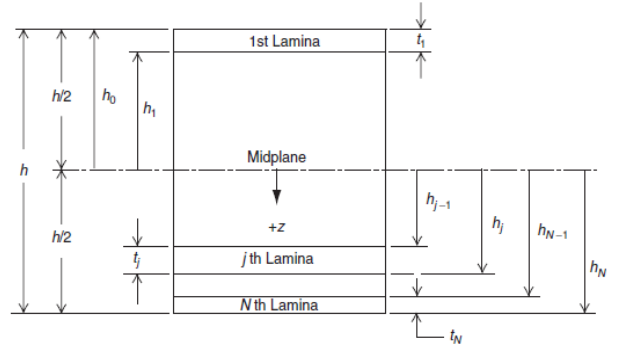

Figure 3: Thickness of laminate [9] 
$E_{x x}=1 / t\left[A_{11}-A_{12}{ }^{2} / A_{22}\right]$ (Young's modulus of laminate along loading (x) direction)

$E_{y y}=1 / t\left[A_{22}-A_{12}{ }^{2} / A 11\right]$ (Young's modulus of laminate perpendicular to loading (y) direction)

For inner layers the critical buckling torque:

$T_{c r i}=2.28 / \sqrt{L} *\left(E_{x x}\right)^{0.375 *\left(E_{y y}\right)^{0.625} *(t)^{2.25} *(D)^{1.25}}$ (18)

For outer layers the critical buckling torque

$T_{\text {cro }}=2 \pi r^{2} t^{*} 0.272 *\left[E_{x x} * E_{y y}\right]^{0.25} *[t / r]^{1.5}$

[14]

$E_{x x}=15.910 \mathrm{GPa}$

$E_{y y}=23.4 \mathrm{GPa}$

$T_{c r i}=3900 \mathrm{Nm}$

$T_{\text {cro }}=4152.17 \mathrm{Nm}$

Average buckling torque, $T a v=4026.09 \mathrm{Nm}$

\subsection{Fabrication of Composites}

An aluminium rod of diameter $19.5 \mathrm{~mm}$ and length of $450 \mathrm{~mm}$ was used as the mandrel. The length was chosen so as to clamp the mandrel at either of the chucks of the filament winding machine. It was first wrapped in cling film to prevent contact between epoxy and mandrel. Next a layer of peel ply is applied and coated evenly with Polyvinyl alcohol (PVA) which acts as a release agent. The fibers are passed through directing combs and the resin pot. The resin pot was then filled with the epoxy resin-hardener mixture taken in the ratio $10: 1$ by weight as specified by the manufacturer. The tensioner is then fixed into position and the fibers are tied to the mandrel.

The motor is switched on causing the spindle to rotate and a small amount of fibers are wound onto the mandrel until the epoxy coated fibers reach the mandrel. The carriage movement is then started and fibers are wound along the mandrel. A breaker switch is connected to a pushrod that is actuated when the carriage reaches the designated end point for winding, causing the direction of winding to be reversed. After the first two layers of $85^{\circ}$ are wound the carriage speed is adjusted to change the angle of winding to $45^{\circ}$ and later to $25^{\circ}$. After all 12 layers have been wound, fibers are disconnected from the mandrel and the mandrel is rotated in the machine for about 5 minutes to ensure uniform distribution of matrix material and to start the precuring phase. The mandrel is then placed in a hot air oven that had been preheated to $120^{\circ} \mathrm{C}$ for about 15 minutes to cure. Post cure the mandrel is cooled rapidly using water at a temperature of about $1^{\circ} \mathrm{C}$ causing the mandrel to shrink slightly and enabling its extraction from the shaft.

Next the shaft is cleaned on the inner surface using sandpaper of 80,120 and 240 grit followed by cleaning of the of surface using acetone as a degreasing agent. Metal inserts are prepared according to the torsion testing machine specifications (as shown in Figure 4) and are bonded to the shaft using Araldite AV 130M and hardener HV 998 which is a bonding agent. It has low out gassing and cures at room temperature to form strong adhesive bonds between the shafts and inserts. The reason for using this type of bonded inserts lies in the application of the shaft being tested. The final use of the shaft will involve bonding to aluminium inserts which have splines that mate with the CV joint for power transmission [15].
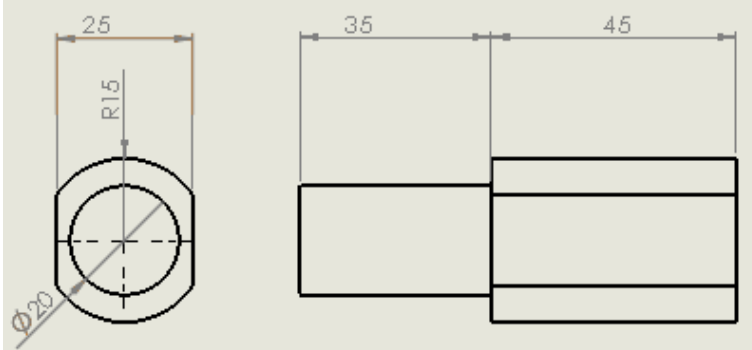

Figure 4: Insert for torsion test (All dimensions in $\mathrm{mm}$ )

\subsection{Torsion Test}

Torsional strength was determined using a torsion testing machine. The shaft was fixed into the machine and a torsional load was applied to the tailstock using a hydraulic motor at a rate of $0.5 \% \mathrm{sec}$. The shaft is said to have failed when a crack starts to form on the surface of the shaft and prevents the shaft from carrying any further loads. Tests were conducted on conditioned samples at a temperature of $25^{\circ} \mathrm{C}$. Five samples were considered for testing. Visual inspection for defects was done prior to testing.

\subsection{Surface morphology of fractured surfaces}

Specimens for morphological studies were prepared from the fractured area of the shaft. The specimens were sized accordingly so as to be mounted in the SEM to analyse and understand the probable failure mechanism. The specimen surfaces were coated with a thin layer of silver by ion sputtering and a $15 \mathrm{kV}$ accelerating voltage was used. The SEM was used in the variable pressure mode.

\section{Results and discussion}

\subsection{Torsion Test}

Figure 5 shows a failed specimen after torsional loading. The torsional strength of the carbon fiber (CF) shafts compared to the OEM steel shaft is presented in Figure 6. The average torsional strength of the carbon fiber shafts is $1770 \mathrm{Nm}$, which is $8.5 \%$ more than the OEM steel shaft $(1630 \mathrm{Nm})$. The carbon fiber shaft fabricated weighs just $0.8 \mathrm{~kg}$ which is $60 \%$ lighter than the OEM steel shaft which weighs $2.5 \mathrm{~kg}$. This can be attributed to the fact that the carbon fiber shaft has a lower density and it is specifically designed to take up the complex loading conditions of a drive shaft. The experimental values are $56 \%$ lower than calculated values. The most likely cause being a lower fiber volume fraction caused by a lower fiber tension provided during the filament winding process. Also there appears to be a collection (agglomeration) of matrix on the surface of the shaft during the curing process which could be caused by the following reasons: (i) excess resin take up during filament winding or (ii) lack of rotation of the shaft during curing process. This leads to an uneven transfer of 
loads between layers of fibers. The strength to weight ratio of composite shaft and OEM steel shaft are 2212 $\mathrm{Nm} / \mathrm{Kg}$ and $652 \mathrm{Nm} / \mathrm{Kg}$ respectively.

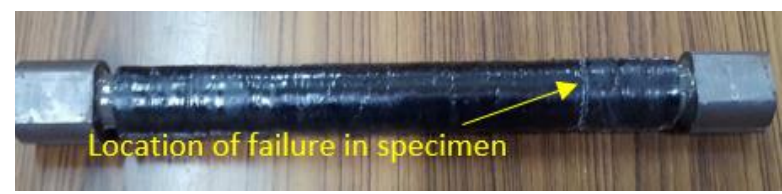

Figure 5: Failed specimen after torsional loading

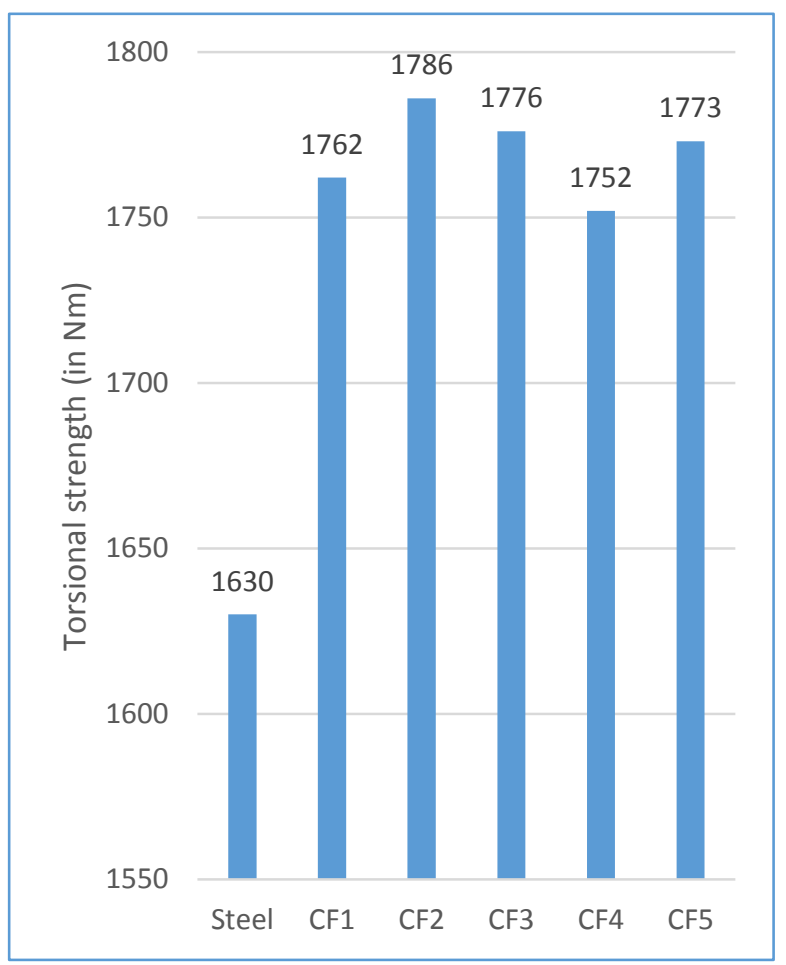

Figure 6 : Torsional strength of shafts

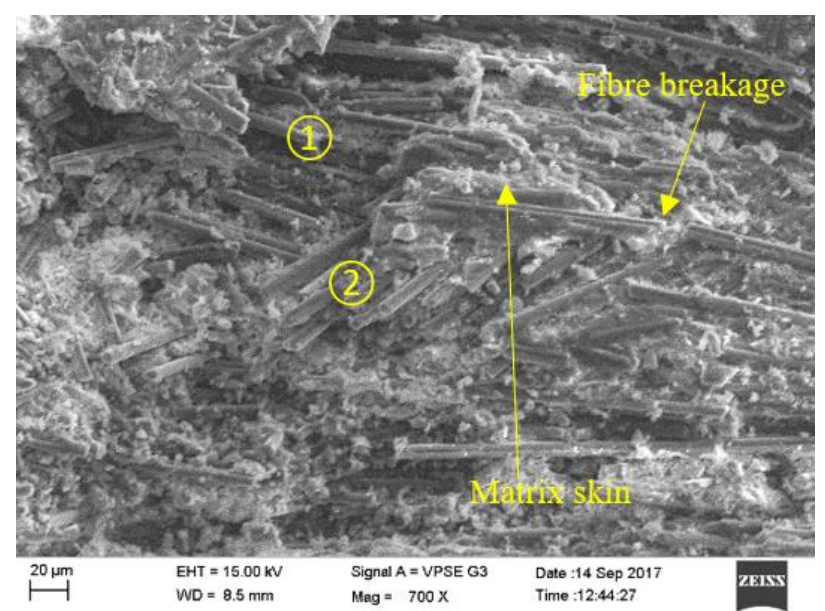

Figure 7 (a): SEM image of carbon fiber shaft torsion specimen

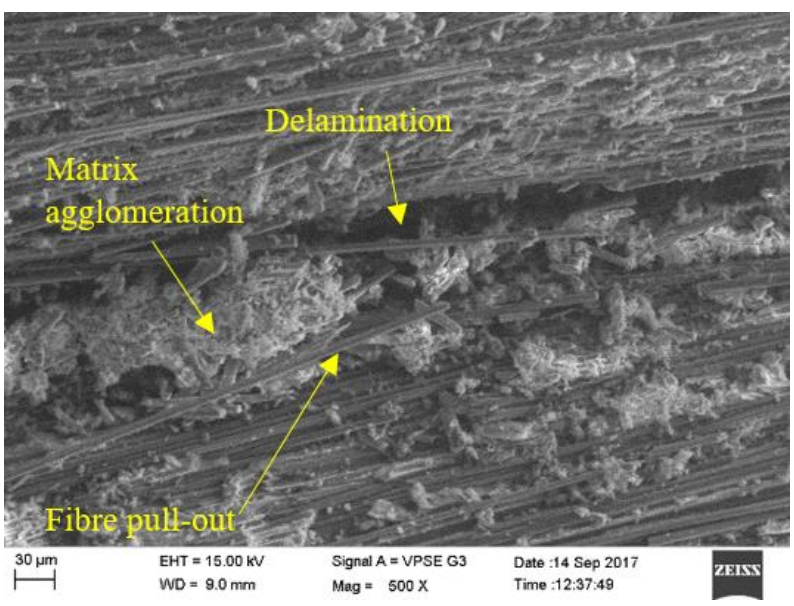

Figure 7 (b): SEM image of carbon fiber shaft torsion specimen

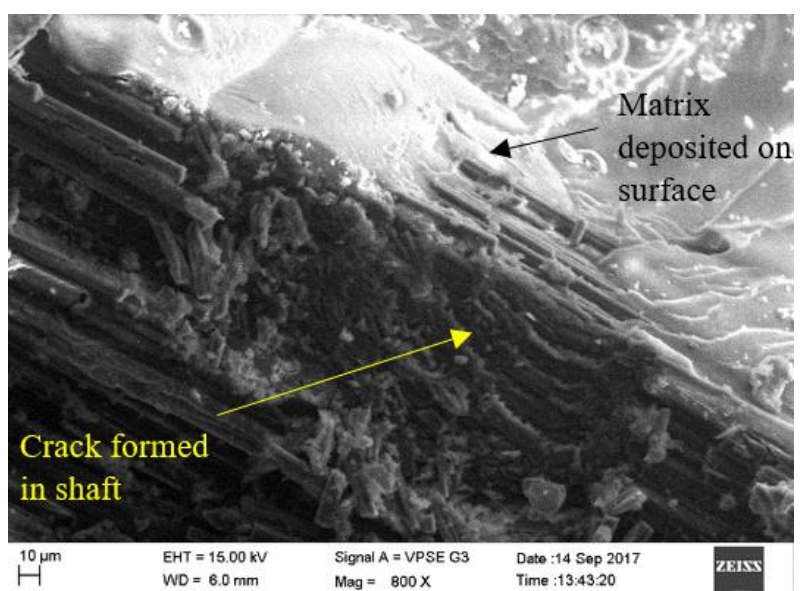

Figure 7 (c): SEM image of carbon fiber shaft torsion specimen

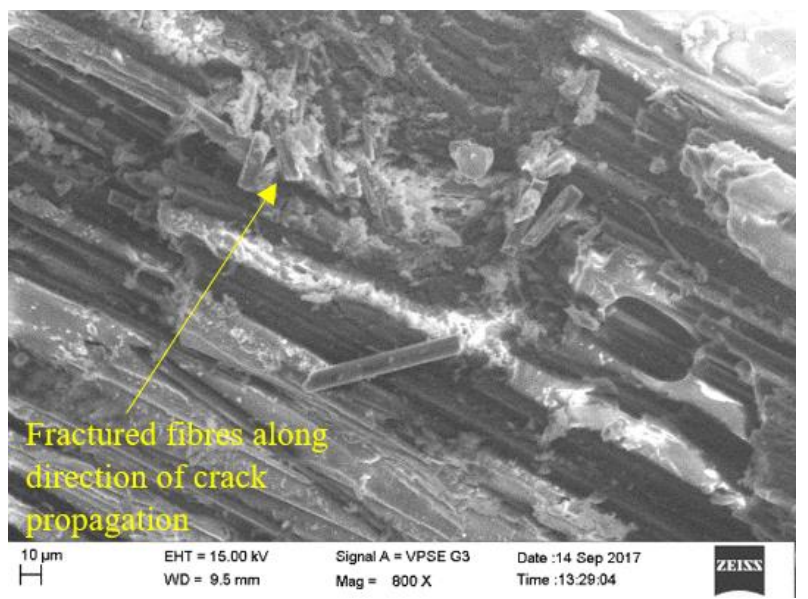

Figure 7 (d): SEM image of carbon fiber shaft torsion specimen

\subsection{Morphology of fractured specimens}

Figures 7 shows micrographs of fractured surfaces. Figure 7(a) depicts the multiple layers of the shaft oriented at the different angles in which each layer of fibers is covered with matrix skin showing good adhesion between the matrix and fibers, zone 1 represents $85^{\circ}$ and zone(2) represents $45^{\circ}$. Fiber breakage due to lateral shift is also seen in Figure 7 (a). Delamination between the layers of the shaft leading to its failure during torsional loading is seen in Figure 7(b). Matrix agglomeration is visible at multiple locations which would lead to a lower 
torsional strength due to uneven transfer of loads between layers. Delamination has further lead to the occurrence of fiber pull-out.

Figure 7(c) represents a section closer to the outer edge of the shaft. Collection of matrix on the surface can be seen which is undesirable and a crack has been formed in the shaft which then propagates towards the lower layers. Figure 7(d) shows the fractured fibers along the loading direction with fiber breakage clearly visible.

\section{Conclusion}

An increase in torsional strength by $8.5 \%$ along with a weight reduction of $60 \%$ leads to an increase of strength to weight ratio by $339 \%$ which indicates that the carbon/epoxy shaft can successfully be used to replace the OEM steel shaft. A deviation from calculated torsional strength of the shaft could be attributed to lower fiber volume fraction obtained during fabrication caused by lower than ideal winding tension. The accumulation of matrix on surface needs to be avoided by making use of an oven with the capability to continuously rotate the shaft while curing. Also excessive resin pickup needs to be prevented during the winding process. Use of shrink tape may help to remove excess resin from the surface of the shaft and further improves dimensional accuracy. Delamination between layers of different orientations of fibers has been identified as the primary mode of failure. Fiber breakage, fiber pull-out and matrix agglomeration further contribute to weakening of the shaft. Increasing the number of filaments in the fibers will help in reduction of delamination as there will be greater surface area for adhesion between matrix and fibers. This is supported by the SEM images which clearly show that there is a matrix skin forming on the fibers indicating good interfacial bonding.

\section{Acknowledgement}

The authors are thankful to Dr. K Jagannath, Head of the Department, Mechanical and Manufacturing Engineering for permitting us to make use of the Advanced Material Testing and Research Laboratory. The authors are also indebted to Dr. Satish Shenoy B, Head of the Department and Mr. Padmaraj N. H., Assistant Professor, Department of Aeronautical and Automobile Engineering for allowing us to use their Advanced Composite and Material Testing Laboratory. The authors thank Dr. M. Vijaya Kini, Associate Professor, Department of Mechanical and Manufacturing Engineering. The authors would also like to thank Dr. Mohandas Chadaga, Head of the Department, Civil Engineering, for permitting us to use the torsion testing machine. The authors thank Mr. Shivprasad Kamath and Mr. Mahesha for assisting us in fabrication of the drive shafts.

\section{References}

1. Carroll Smith "Tune to Win" Aero Publishers, INC. (1978) ISBN:978-0-87938-071-7

2. Baja, S. A. E. "2015 Collegiate Design Series."(2014)

3. Daniel, Isaac M., Ori Ishai, Issac M. Daniel, and Ishai Daniel. Engineering mechanics of composite materials. 3. New York: Oxford university press, (1994)

4. Moorthy, R. Srinivasa, Yonas Mitiku, and K. Sridhar. "Design of automobile driveshaft using carbon/epoxy and kevlar/epoxy composites." . AJER 2, 10 (2013): 173-179.

5. Hatwar, Pankaj K., and R. S. Dalu. "Design and Analysis of Composite Drive Shaft.". IJSR 4, 4 ISSN (Online): 2319-7064(2013)

6. Rajmane, S. M., and M. A. Chopade. "Investigation of Effect of Stacking Sequence and Fiber Orientation on Maximum Torque Transmission Capacity of a Composite Automobile Driveshaft by Analytical \& FEA Methods." IJAIEM 3, 11 (2014): 31-37.

7. Reddy, P. Satheesh Kumar, Ch Nagaraju, and T. Hari Krishna. "Optimum design and analysis of filament wound composite tubes in pure and combined loading." IJERT 1, 8 (2012).

8. Bankar, Harshal, Viraj Shinde, and P. Baskar. "Material optimization and weight reduction of drive shaft using composite material." IOSR-JMCE 10, 1 (2013): 39-46.

9. Mallick, Pankar K. Fiber-reinforced composites: materials, manufacturing, and design. CRC Press $\mathbf{3}^{\text {rd }}$ Edition ISBN:1420005987 (2007)

10. Formosa Plastics Corporation,(2014) "Tairyfil Data Sheet".

11. Cai, Z. H. O. N. G., T. Gutowski, and S. Allen. "Winding and consolidation analysis for cylindrical composite structures." J. Compos. Mater. 26, 9 (1992): 1374-1399.

12. Atul Limited "LAPOX L12/K6". 2 (2012)

13. Patil, Sagar D. ,DS Chavan, MV Kavade, "Investigation of Composite Torsion Shaft for Torsional Buckling Analysis using Finite Element Analysis"." IOSR-JMCE.4, 3 (2012): 26-31.

14. Badie, M. A., E. Mahdi, and A. M. S. Hamouda. "An investigation into hybrid carbon/glass fiber reinforced epoxy composite automotive drive shaft."Mater.Des. 32, 3 (2011): 1485-1500.

15. Sharma, Ambuj, James M. Nelson, Douglas P. Goetz, Amit Patel, Paul Sedgwick, Wendy Thompson, Travis Gorsuch, and Dave Knauff. "The Impact of Nanosilica-Modified Epoxy Resins on the Design and Performance of Filament-Wound Drive Shafts." CAMX Conference Proceedings, pp. 26-29. (2015). 